\title{
Sun-induced fluorescence - a new probe of photosynthesis: First maps from the imaging spectrometer HyPlant
}

Rascher, Uwe ; Alonso, L ; Burkart, Andreas ; Cilia, C ; Cogliati, S ; Colombo, R ; Damm, Alexander ; Drusch, Matthias ; Guanter, Luis ; Hanuš, Jan ; Hyvärinen, Timo ; Julitta, T ; Jussila, Jouni ; Kataja, Kari ; Kokkalis, P ;

Kraft, S ; Kraska, Thorsten ; Matveeva, Maria ; Moreno, Jose ; Muller, Onno ; Panigada, C ; Pikl, M ; Pinto, Francisco ; Prey, L ; Pude, Ralf ; Rossini, Micol ; Schickling, Anke ; Schurr, U ; Schüttemeyer, D ; Verrelst, Jochem ; Zemek, F

\begin{abstract}
Variations in photosynthesis still cause substantial uncertainties in predicting photosynthetic $\mathrm{CO} 2$ uptake rates and monitoring plant stress. Changes in actual photosynthesis that are not related to greenness of vegetation are difficult to measure by reflectance based optical remote sensing techniques. Several activities are underway to evaluate the sun-induced fluorescence signal on the ground and on a coarse spatial scale using space-borne imaging spectrometers. Intermediate-scale observations using airborne-based imaging spectroscopy, which are critical to bridge the existing gap between small-scale field studies and global observations, are still insufficient. Here we present the first validated maps of sun-induced fluorescence in that critical, intermediate spatial resolution, employing the novel airborne imaging spectrometer HyPlant. HyPlant has an unprecedented spectral resolution, which allows for the first time quantifying sun-induced fluorescence fluxes in physical units according to the Fraunhofer Line Depth Principle that exploits solar and atmospheric absorption bands. Maps of sun-induced fluorescence show a large spatial variability between different vegetation types, which complement classical remote sensing approaches. Different crop types largely differ in emitting fluorescence that additionally changes within the seasonal cycle and thus may be related to the seasonal activation and deactivation of the photosynthetic machinery. We argue that sun-induced fluorescence emission is related to two processes: (i) the total absorbed radiation by photosynthetically active chlorophyll and (ii) the functional status of actual photosynthesis and vegetation stress.
\end{abstract}

DOI: https://doi.org/10.1111/gcb.13017

Posted at the Zurich Open Repository and Archive, University of Zurich

ZORA URL: https://doi.org/10.5167/uzh-117074

Journal Article

Accepted Version

Originally published at:

Rascher, Uwe; Alonso, L; Burkart, Andreas; Cilia, C; Cogliati, S; Colombo, R; Damm, Alexander; Drusch, Matthias; Guanter, Luis; Hanuš, Jan; Hyvärinen, Timo; Julitta, T; Jussila, Jouni; Kataja, Kari; Kokkalis, P; Kraft, S; Kraska, Thorsten; Matveeva, Maria; Moreno, Jose; Muller, Onno; Panigada, C; Pikl, M; Pinto, Francisco; Prey, L; Pude, Ralf; Rossini, Micol; Schickling, Anke; Schurr, U; Schüttemeyer, D; Verrelst, Jochem; Zemek, F (2015). Sun-induced fluorescence - a new probe of photosynthesis: First maps from the imaging spectrometer HyPlant. Global Change Biology, 21(12):4673-4684.

DOI: https://doi.org/10.1111/gcb.13017 
Received Date : 29-Nov-2014

Accepted Date : 26-May-2015

Article type : Technical Advances

\section{Sun-induced fluorescence - a new probe of photosynthesis: First maps from the imaging spectrometer HyPlant}

U. Rascher ${ }^{1, ~ *}$, L. Alonso ${ }^{2}$, A. Burkart ${ }^{1}$, C. Cilia ${ }^{1,3}$, S. Cogliati $^{3}$, R. Colombo ${ }^{3}$, A. Damm $^{4}$, M. Drusch ${ }^{5}$, L. Guanter ${ }^{6}$, J. Hanus ${ }^{7}$, T. Hyvärinen ${ }^{8}$, T. Julitta ${ }^{3}$, J. Jussila ${ }^{8}$, K. Kataja ${ }^{8}$, P.

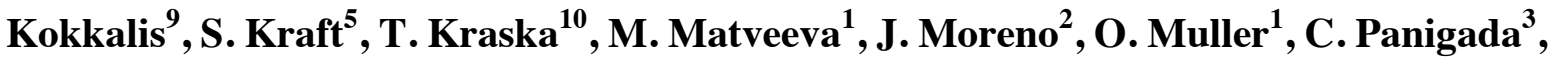

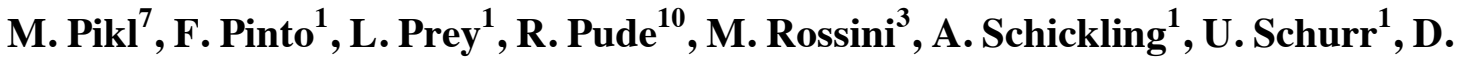
Schüttemeyer $^{5}$, J. Verrelst ${ }^{2}$, F. Zemek ${ }^{7}$

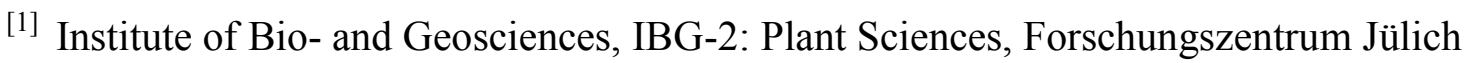
GmbH, Leo-Brandt-Str., 52425 Jülich, Germany

[2] Department of Earth Physics and Thermodynamics, University of Valencia, Dr Moliner, 50, 46100 Burjassot, Valencia, Spain

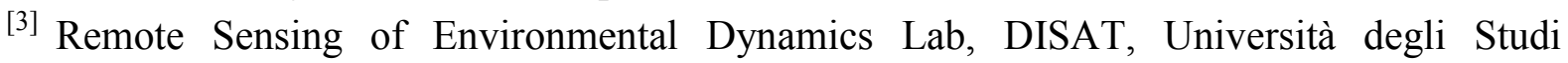
Milano-Bicocca, Milano, Italy

[4] Remote Sensing Laboratories, University of Zurich, Winterthurerstrasse 190, 8057 Zurich, Switzerland

${ }^{[5]}$ European Space Agency (ESA), ESTEC, Keplerlaan 1, 2200 AG Noordwijk, Netherlands

${ }^{[6]}$ Institute for Space Sciences, Free University of Berlin, Carl-Heinrich-Becker-Weg 6-10, 12165 Berlin, Germany

[7] Global Change Research Centre AS CR, Bělidla 986/4a, 60300 Brno, Czech Republic

${ }^{[8]}$ Specim, Spectral Imaging Ltd., Teknologiantie 18A, 90590 Oulu, Finland

[9] Institute for Astronomy, Astrophysics, Space Applications and Remote Sensing, National Observatory of Athens, Athens, 15236, Greece

${ }^{[10]}$ Field Lab Campus Klein-Altendorf, Agricultural Faculty, University of Bonn, Klein-Altendorf 3, 53359 Rheinbach, Germany

* Correspondence to: U. Rascher, e-mail u.rascher@fz-juelich.de, tel. +49-(0)2461-61 2638;

fax. $+49-(0) 2461-612492$

This article has been accepted for publication and undergone full peer review but has not been through the copyediting, typesetting, pagination and proofreading process, which may lead to differences between this version and the Version of Record. Please cite this article as doi: $10.1111 / \mathrm{gcb} .13017$

This article is protected by copyright. All rights reserved. 
Keywords:

Photosynthesis - sun-induced fluorescence - remote sensing - HyPlant - chlorophyll fluorescence - FLEX - imaging spectroscopy - airborne measurements - vegetation monitoring

\section{Abstract}

Variations in photosynthesis still cause substantial uncertainties in predicting photosynthetic $\mathrm{CO}_{2}$ uptake rates and monitoring plant stress. Changes in actual photosynthesis that are not related to greenness of vegetation are difficult to measure by reflectance based optical remote sensing techniques. Several activities are underway to evaluate the sun-induced fluorescence signal on the ground and on a coarse spatial scale using space-borne imaging spectrometers. Intermediate-scale observations using airborne-based imaging spectroscopy, which are critical to bridge the existing gap between small-scale field studies and global observations, are still insufficient. Here we present the first validated maps of sun-induced fluorescence in that critical, intermediate spatial resolution, employing the novel airborne imaging spectrometer HyPlant. HyPlant has an unprecedented spectral resolution, which allows for the first time quantifying sun-induced fluorescence fluxes in physical units according to the Fraunhofer Line Depth Principle that exploits solar and atmospheric absorption bands. Maps of sun-induced fluorescence show a large spatial variability between different vegetation types, which complement classical remote sensing approaches. Different crop types largely differ in emitting fluorescence that additionally changes within the seasonal cycle and thus may be related to the seasonal activation and deactivation of the photosynthetic machinery. We argue that sun-induced fluorescence emission is related to two processes: (i) the total absorbed radiation by photosynthetically active chlorophyll and (ii) the functional status of actual photosynthesis and vegetation stress.

\section{Introduction}

Terrestrial plant photosynthesis constitutes a major flux of carbon and water exchange with the atmosphere. Variations of light absorption due to different canopy structures and in the efficiency of the photosynthetic machinery cause great variations in diurnal, seasonal, and spatial patterns of photosynthesis. These spatio-temporal variations cannot to date be measured 
directly, and modeling still suffers substantial uncertainties in estimating and predicting photosynthetic carbon and water exchange especially on the local and regional scale (Dolman et al. 2009). There is currently no dedicated satellite system available that can measure photosynthesis directly, and remote sensing instruments on satellites only detect greenness and the amount of chlorophyll. Attempts to use the reflectance signal at $531 \mathrm{~nm}$ and the Photochemical Reflectance Index (PRI) to quantify photosynthetic efficiency (Asner et al., 2006) are challenged by the great contamination of the signal by various leaf pigments and canopy structure (Barton \& North, 2001, Garbulsky et al., 2011, Hall et al. 2008, Hilker et al. 2009).

Sun-induced chlorophyll fluorescence signal is explored as a novel remote sensing method, notable for its potential to be used as a direct indicator of photosynthetic efficiency. Fluorescence is emitted from the cores of the photosynthetic apparatus and can be detected passively at leaf to canopy level (Rascher et al., 2009) using high-resolution spectrometers in combination with the Fraunhofer Line Depth (FLD) retrieval principle (Malenovsky et al., 2009, Meroni et al., 2009). [See supplementary information (S1) for background on sun-induced fluorescence and the measurement principle]. Recently, the European Space Agency (ESA) supported this attempt by selecting the FLEX mission (FLEX: FLuorescence EXplorer) as one of their candidate Earth Explorer missions. The FLEX mission aims to measure the full spectrum of sun-induced fluorescence emission $(670-780 \mathrm{~nm})$ with a spatial resolution of 300 meters and a repeated global coverage. FLEX will exploit the full spectral window of fluorescence emission with a high spectral resolution of $0.2 \mathrm{~nm}$ and a high SNR allowing to retrieve fluorescence in the solar and atmospheric absorption bands.

Fluorescence can be retrieved on coarse spatial resolution using existing space-borne imaging spectrometers. The first global maps of fluorescence were derived using data from the Greenhouse gases Observing Satellite (GOSAT) (Frankenberg et al., 2011, Guanter et al., 2007, Guanter et al., 2012, Joiner et al., 2011), demonstrating novel information on the spatio-temporal variability of sun-induced fluorescence and plant photosynthesis on the spatial scale of $2^{\circ}$. Recently, Joinier et al (2013) also explored data from the GOME-2 satellite, and fluorescence was derived as 10 days to monthly averages on the $0.5^{\circ}$ grid. These data were used to demonstrate that global models may greatly underestimate gross primary productivity (GPP) in the high-production agricultural regions during main vegetation period (Guanter et al. 2014).

Small-scale local studies focusing on the quantification of top-of-canopy sun-induced fluorescence have demonstrated the potential of sun-induced fluorescence to track diurnal,

This article is protected by copyright. All rights reserved. 
seasonal, and species-specific adaptation of photosynthesis. For example, Damm et al. (2010) showed that sun-induced fluorescence improves forward modeling of diurnal courses of GPP in corn fields, and in a rice field. Rossini et al. (2010) showed seasonal dynamics in the fluorescence signal that were related to changes in structure-function relations. On the intermediate scale, i.e. covering the spatial scale from meters to kilometers, only a few case studies are available, which either recorded fluorescence in relative units (Rascher et al., 2009) or use light-weight spectrometers on UAVs requiring a series of empirical corrections (Zarco-Tejada et al., 2013), yet these maps still lack a proper evaluation. This intermittent spatial scale, however, is of utmost importance to better understand the variability in canopy photosynthesis from the single plant to the field (Rascher et al., 2011, Rascher \& Nedbal, 2006, Schurr et al., 2006), which is a challenge for precision agriculture and for measuring and managing crop performance related to different crop varieties and management practices. For flux modeling, this intermittent spatial scale (also referred to as "mesoscale") has been identified as revealing the most uncertainties by scaling local process models to the regional and global scale (Dolman et al., 2009). Thus, direct measurements of functional vegetation properties or photosynthetic rates would greatly facilitate our understanding and prediction of vegetation carbon and water fluxes as well as validation strategies for current and future satellite-based fluorescence measurements.

To address the lack of an intermittent spatial scale, Forschungszentrum Jülich (Germany) in cooperation with the Finnish company Specim (www.specim.fi) developed the airborne imaging spectrometer HyPlant, which was specifically designed to monitor vegetation and retrieve fluorescence in the atmospheric absorption bands (Meroni et al., 2009). The instrument is a push-broom imager consisting of two modules that are aligned and mounted on a single rack (Fig 1a, b). One module measures surface radiance in the spectral range of 380 to $2500 \mathrm{~nm}$, and the second module has a high spectral resolution of $0.25 \mathrm{~nm}$ in the red and far-red spectral range and was specifically designed for fluorescence retrieval between 670 and 780 $\mathrm{nm}$ (Fig 1c, d). A summary and details on the characteristics of HyPlant are given in Table 1.

HyPlant constitutes a state of the art imaging spectrometer complementing the existing fleet of operational airborne spectrometers, such as APEX (http://www.apex-esa.org/), AVIRIS (http://aviris.jpl.nasa.gov/), HySpex (http://www.opairs.aero/hyspex_en), or CASI (http://www.itres.com/). This new airborne instrument was designed with the aim to provide unprecedented spectrally resolution data in the red spectral region to specifically enable 
fluorescence retrieval. HyPlant was first operated in a series of campaigns at the end of 2012, and flight lines were recorded from two nominal flight altitudes, 600 and 1,780 $\mathrm{m}$ above ground, corresponding to a spatial resolution of 1 and $3 \mathrm{~m}$, respectively. Based on selected flight lines, we characterized the spectral, spatial, and radiometric performance of the instrument in detail. High resolution irradiance spectra, simulated using the atmospheric radiative transfer model MODTRAN-5 (Berk et al., 2004), were gradually degraded to the nominal characteristics of the sensor elements. Parameters for degrading the modeled data were fine tuned for best correlation with measured spectra (see Materials for description of this procedure). Previous studies have delivered only singular, airborne fluorescence maps giving fluorescence in relative units (Panigada et al., 2014, Rascher et al., 2009) or have systematically overestimated airborne fluorescence (Guanter et al., 2007). HyPlant permits for the first time the possibility of high-resolution spectroscopy in the red region for retrieval of sun-induced fluorescence in the spectrally narrow oxygen absorption bands using the dedicated "fluorescence module."

\section{Material and Methods}

\section{Radiometric and spectral characterization of HyPlant}

The spectral performance of the HyPlant sensor was investigated by evaluating two parameters describing the Spectral Response Function (SRF) of a spectral pixel, namely the position within the detector array and the spectral band width (Full width at Half Maximum $=$ FWHM). Both parameters were investigated in pre-defined positions of the detector array. The quantification was based on comparing measured (HyPlant) and modeled reference radiance signals in pre-defined atmospheric absorption features. The reference radiance signal was modeled with MODTRAN-5 (Berk et al., 2004) in the highest spectral resolution, i.e. 0.0057 $\mathrm{nm}$ (at $760 \mathrm{~nm}$ ). To avoid misinterpretations caused by spatial heterogeneity, we only analyzed pixels across track covering a homogeneous area.

Modeled spectra were convolved considering: i) a variable FWHM $\epsilon$ [0.1 to 0.4$] \mathrm{nm}$ and FWHM $\epsilon[1.0$ to 20.0$] \mathrm{nm}$; and ii) a variable spectral shift (SS) $€[-0.5$ to 0.5$] \mathrm{nm}$ and $\mathrm{SS} \epsilon[-2.0$ to $2.0 \mathrm{Jm}$ for the fluorescence and dual-channel module, and iii) a fixed spectral sampling distance interval for each FWHM (SSI $=0.5 \times$ FWHM). Parameters that resulted in the highest correlation between modeled and measured spectra represent the spectral characteristics of the sensor in flight operation. Additionally, we evaluated radiometric performance by

This article is protected by copyright. All rights reserved. 
investigating the occurrence of bad pixels, the signal-to-noise ratio, and other radiometric effects, which are summarized in Table 1.

\section{Processing of $\mathrm{HyPlant}$ data, retrieval of sun-induced fluorescence $\left(\mathrm{F}_{760}\right)$}

Image pre-processing

The instrument's dark signal was linearly removed, pixel by pixel using a dark frame image acquired by closing the shutter of the camera immediately after each line acquisition. Data values were then converted from digital numbers to radiance $\left(\mathrm{mW} \cdot \mathrm{m}^{-2} \mathrm{str}^{-1} \mathrm{~nm}^{-1}\right)$ considering the integration time during acquisition and using a radiometric calibration coefficient estimated for each pixel of the sensor using detailed laboratory calibration by the manufacturer of the camera. Navigation data provided by the GPS/IMU of HyPlant and a Digital Elevation Model (DEM) of the region were used for geometric correction of the images. Accurate overlapping between the two modules of HyPlant was achieved after a boresight calibration, where the alignment of both modules with respect to the GPS/IMU, was corrected. All pre-processing steps were performed using the software CaliGeo Pro (Specim, Finland), which provides a user interface for interactively perform geo-rectification of a single line or run a group of them in a batch mode.

\section{Sun-induced fluorescence retrieval $\left(F_{760}\right)$}

The emitted chlorophyll fluorescence signal adds to the radiation reflected by a vegetation canopy (Meroni et al., 2010), supplementary information 1). Assuming Lambertian surface reflectance $(\rho)$, radiance leaving the surface $(L)$ measured by a sensor at a specific wavelength

$(\lambda)$ can be expressed as

$$
L_{\lambda}=L_{\lambda}^{p}+\frac{1}{\pi} \frac{\left(E_{\lambda}^{g} \rho_{\lambda}+S I F_{\lambda}\right) \pi \tau_{\lambda}}{1-S_{\lambda} * \rho_{\lambda}}
$$

where $L^{p}$ is the path of scattered radiance, $E^{g}$ is the global irradiance (including direct and diffuse fluxes) arriving at the surface, $\tau \uparrow$ is the upwelling transmittance, and $S$ is the spherical albedo. To decouple sun-induced fluorescence $(\mathrm{F})$ and $\rho$, at-sensor radiance 
measurements of a vegetation target inside $(i)$ and outside $(o)$ of an absorption band are required. For the airborne case, such measurements can be written as:

$$
\left.\begin{array}{l}
L_{i}=L_{i}^{p}+\frac{1}{\pi} \frac{\left(E_{i}^{g} \rho_{i}+F_{i}\right) \pi \tau_{i}}{1-S_{i} * \rho_{i}} \\
L_{o}=L_{o}^{p}+\frac{1}{\pi} \frac{\left(E_{o}^{g} \rho_{0}+F_{0}\right) \pi \tau_{o}}{1-S_{0} * \rho_{o}}
\end{array}\right\}
$$

$L_{\lambda}$ is known directly from the measurement itself and the terms $E, L^{p}, S$, and $T$ are obtained for each observation using MODTRAN-5 (Berk et al., 2004) in combination with the MODTRAN-interrogation technique as described in Damm et al. (2015) or Verhoef and Bach $(2003,2007)$. Thus, the system of equations (eq 2$)$ contains only four unknowns: $F_{i}, F_{o}, \rho_{i}$, and $\rho_{o}$, which are spectral reflectance and fluorescence values, inside and outside of the absorption bands.

In this study, we exploited the broader $\mathrm{O}_{2}$ - $\mathrm{A}$ oxygen absorption band around $760 \mathrm{~nm}$ and used the 3FLD method (Maier et al., 2003). The 3FLD method is a modification of the original Fraunhofer Line Depth (FLD) approach (Plascyk \& Gabriel, 1975), allows to linearly relate $R$ and $\mathrm{F}$ inside and outside of the $\mathrm{O}_{2}-\mathrm{A}$ absorption band, and was shown to provide reasonable accuracy by being robust against sensor noise (Damm et al., 2011). Sun-induced fluorescence at $760 \mathrm{~nm}\left(\mathrm{~F}_{760}\right)$ was accordingly calculated as,

$$
F_{760}=B\left[\frac{X_{i}\left(E_{0}^{g}+X_{0}-S_{0}\right)-A X_{0}\left(E_{i}^{g}+X_{i}-S_{i}\right)}{B\left(E_{0}^{g}+X_{0}-S_{0}\right)-A\left(E_{i}^{g}+X_{i}-S_{i}\right)}\right]
$$

with

$$
X_{j}=\frac{\left(L_{j}-L_{j}^{p}\right)}{\tau \uparrow_{j}}, \quad j=i, o
$$

and

$$
\left.\begin{array}{l}
\rho_{i}=A \rho_{o} \\
F_{i}=B F_{o}
\end{array}\right\}
$$


$A$ is the factor relating $\rho_{i}$, and $\rho_{o}$ and was derived from linear interpolation of $\rho$ of the left and right $\mathrm{O}_{2}-\mathrm{A}$ band shoulders with

$$
\begin{aligned}
& A=\frac{\rho_{75 \mathrm{~g}} \omega_{1}+\rho_{771} \omega_{2}}{\rho_{75 \mathrm{~s}}} \\
& \text { and } \\
& \omega_{1}=\frac{771-760}{771-758}, \text { and } \omega_{2}=\frac{760-758}{771-758}
\end{aligned}
$$

Sensor noise can affect the retrieval; to minimize such noise impacts, we used the average of ten bands located on the left $(753 \mathrm{~nm})$ and right $(771 \mathrm{~nm})$ shoulders of the $\mathrm{O}_{2}$-A band. $B$ is the factor relating $F_{i}$ and $F_{o}$ (inside and outside the $\mathrm{O}_{2}$-A band) and was fixed to a value of 0.8 , justified by simulations and experiments (Alonso et al., 2008, Rascher et al., 2009). Measurements were taken under stable atmospheric conditions, and all atmospheric functions were estimated for a flat surface assuming a standard atmosphere to parameterize the radiative transfer model (RTM). Solar zenith, solar azimuth, ground elevation, and sensor elevation were adjusted to the measurement times. However, inaccuracies in the atmospheric modeling (e.g., slightly incorrect assumptions on actual aerosol load) and instrumental errors such as spectral shift residuals, vignetting effects, or other small deviations from nominal sensor characteristics cause miscalculations of the retrieved $\mathrm{F}_{760}$ signals (Damm et al., 2011). We compensated for the impact of such sources of uncertainty by using a semi-empirical correction called "transmittance correction" for each scan line across track. This technique employs reference surfaces, which are free of any $\mathrm{F}_{760}$ emission (e.g., bare soil) to adjust the upward transmittance term inside the absorption feature $\tau_{\circ o}^{i}$ (see (Damm et al., 2014) for details on this method).

It is important to note that the correction factor depends on the actual atmospheric status and illumination/observation geometry. Spatial distances between reference surfaces and vegetation targets in combination with changing flight and surface height during data acquisition, as well as small spatial variations of atmospheric properties (i.e., aerosol load) can cause deviations between correction factors obtained over a reference surface and the correction factor needed for a certain vegetation target. To extract the most representative

This article is protected by copyright. All rights reserved. 
correction factor for each vegetation target, we applied a spatial interpolation of distinct retrievals of the correction factor considering the surface height.

\section{Calculation of vegetation products}

From top-of-canopy reflectance data, we produced a pseudo-RGB composite using the radiance bands of $695.54 \mathrm{~nm}, 708.26 \mathrm{~nm}$, and $676.54 \mathrm{~nm}$ for the red, green, and blue channel of the image, respectively (Fig 3a). Top-of-canopy reflectance was calculated by modeling atmospheric transmission using MODTRAN-5 that was parameterized by the measured meteorological conditions. The top-of canopy radiant intensity was extracted for $758 \mathrm{~nm}$ close to the oxygen-A absorption line. The Normalized Difference Vegetation Index (NDVI) is a traditional, multi-spectral index based on the difference in canopy reflectance at red and near-infrared wavelengths. The NDVI is sensitive to canopy greenness, which is a composite property including canopy cover, leaf area, and canopy architecture (Carlson \& Ripley, 1997). We calculated a narrow band NDVI from the spectral band that was closest to the nominal wavelength as:

$$
\mathrm{NDVI}=\left(\mathrm{R}_{758}-\mathrm{R}_{670}\right) /\left(\mathrm{R}_{758}+\mathrm{R}_{670}\right)
$$

where $\mathrm{R}_{\mathrm{x}}$ denotes for the reflectance at this specific wavelength.

While the NDVI relies on two wavebands only, the Enhanced Vegetation Index (EVI) corrects for structural and atmospheric effects by differently weighting the spectral regions and by taking an additional blue waveband into consideration. We used the weighting factors of MODIS and selected the optimal wavebands for our sensor (eq. 9; modified according to Huete et al. 1997).

$$
E V I=\frac{R_{758}-R_{670}}{R_{758}+6 R_{670}-7.5 R_{470}+1}
$$

$\mathrm{R}_{\mathrm{x}}$ denotes for the reflectance at this specific wavelength.

More advanced methods using machine learning regression algorithms are available. Such methods generally provide a better estimate of chlorophyll content through using the full 
hyperspectral reflectance signature. We chose an advanced retrieval algorithm based on Gaussian processes regression according to Verrelst et al. (2013). Gaussian processes regression is based on non-parametric Bayesian probabilistic statistics, making no assumptions on the data distribution. It fits a non-linear regression of reflectance spectra combinations, which indicates the relative relevance of the spectral bands during model development and provide an uncertainty estimate for each pixel along with the variable mean estimate (Verrelst et al., 2012).

Land cover classification was obtained through a supervised classification approach. A Spectral Angle Mapper (SAM) algorithm was applied to the first 10 bands of the Minimum Noise Fraction (MNF) transformation calculated from the 1,024 bands of HyPlant fluorescence module. Spectral endmembers for the SAM algorithm were selected for each of the most representative cover types shown in Figure 4.

\section{Validation of fluorescence maps}

The validation of retrieved fluorescence values includes two strategies: i) a comparison with top-of-canopy fluorescence simultaneously measured on ground using established high resolution spectrometers (Meroni et al., 2011, Rossini et al., 2010): and ii) a relative comparison between fluorescence measured over the same area but in two contrasting flight altitudes. HyPlant data used for the validation were collected on 23 August 2012 over an agricultural site around noon in flight heights of $600 \mathrm{~m}$ agl (12:50 local time) and 1,780 $\mathrm{m}$ agl (13:23 local time) (position of the ground reference measurements were $50.863887 \mathrm{~N}$, $6.450933 \mathrm{E}$ for the high value (recorded at sugar beet) and $50.869316 \mathrm{~N}, 6.451987 \mathrm{E}$ for the lower value (recorded at grassland). See supplementary information (S2) for more details on the validation measurements on ground.

\section{Results and Discussion}

The spectral and radiometric characteristics of the fluorescence module of HyPlant allows for the first time the quantification of sun-induced fluorescence at $760 \mathrm{~nm}\left(\mathrm{~F}_{760}\right)$ in validated physical units from airborne data with high spatial resolution (Figs. 2, 4 and 5). HyPlant fluorescence maps showed good agreement with simultaneous ground and top-of-canopy fluorescence measurements. A highly significant relationship was established

This article is protected by copyright. All rights reserved. 
between ground fluorescence fluxes and HyPlant maps derived from both flight heights (Fig $2 \mathrm{a} ; \mathrm{R}^{2}=0.97, \mathrm{RMSE}=0.166 \mathrm{~mW} \mathrm{~m}^{-2} \mathrm{~nm}^{-1} \mathrm{sr}^{-1}, \mathrm{rRMSE}=8.7 \%$ ) with a slope close to 1 .

The agreement of fluorescence maps flown at 600 and 1,780 m above ground was further confirmed using an extended set of land cover types (Fig 2b). Irrespective of the flight height, both HyPlant fluorescence maps are only slightly affected by offsets, and selected values are close to the $1: 1$ line $\left(\mathrm{R}^{2}=0.99, \mathrm{RMSE}=0.165 \mathrm{~mW} \mathrm{~m}^{-2} \mathrm{~nm}^{-1} \mathrm{sr}^{-1}, \mathrm{rRMSE}=10.16 \%\right)$. There is a slight additive offset where fluorescence values obtained from the high flight are systematically lower compared to fluorescence retrieved from the low flight. We consider this deviation to be realistic and related to a short time delay of data acquisitions. The high flight was performed roughly 40 min after the low flight, while the sun elevation angle had already decreased during this time of the day.

Maps of $\mathrm{F}_{760}$ from two selected agricultural sites show clearly novel information on plant structure-function relationships. In Figure 3, the experimental research campus of Bonn University is mapped. $\mathrm{F}_{760}$ shows several note-worthy features. (i) All non-vegetated surfaces have fluorescence values at or very close to zero including streets, rooftops, bare and foil-covered soil (A in Fig 3). (ii) Apple tree plantations (B and C in Fig 3) show fluorescence values just below $1 \mathrm{~mW} / \mathrm{m}^{2} \cdot \mathrm{sr} \cdot \mathrm{nm}$. This fluorescence value remains low in commercial (b) and experimental plantations (c). (iii) Sugar beet fields (D in Fig. 3) have consistently the highest fluorescence values reaching $2 \mathrm{~mW} \mathrm{~m} \mathrm{~m}^{-2} \cdot \mathrm{sr}^{-1} \cdot \mathrm{nm}^{-1}$. (iv) High fluorescence values around $1.5 \mathrm{~mW} \mathrm{~m} \mathrm{~m}^{-2} \cdot \mathrm{sr}^{-1} \cdot \mathrm{nm}^{-1}$ were also observed from the experimental plots of the $\mathrm{C}_{4}$ plants Miscanthus sp. and corn (E in Fig 3).

The high fluorescence values of the sugar beet and corn fields suggests that sun-induced fluorescence measures more than just greenness. Corn, apple trees, and other annual crops were already approaching senescence during the time of observation (end of August 2012) despite the still green leaf-material. Only sugar beet, naturally a biannual crop but commercially harvested in late autumn, has a dense and fully photosynthetically active canopy. Also the perennial $\mathrm{C}_{4}$ grass Miscanthus shows no signs of autumn senescence, which may be reflected in high fluorescence values that may indicate a fully functioning photosynthetic machinery in a dense green canopy. However, based on this first data set we cannot finally unravel the effects of a denser canopy from the contribution of changes in the functional status of photosynthesis. Our findings are also in agreement with the hypothesis recently derived from space-borne measurements, where agricultural regions dominated by $\mathrm{C}_{4}$ have been found to show the relative highest fluorescence signal in late summer (Guanter 
et al., 2014). We can confirm this finding and associate absolute physical numbers of fluorescence emission per area with these vegetation types.

In a second step, we selected flight lines covering a large agricultural scene close to the Forschungszentrum Jülich, which was mapped at two different time periods of the vegetation cycle (Figs. 4 and 5). The first measurements took place late summer 2012, a second survey was performed early summer 2013. From these flight lines, we calculated the brightness in the far-red (Fig 4b), the Normalized Difference Vegetation Index (NDVI, Fig 4c and 5b), the Enhanced Vegetation Index (EVI, Fig 5c) a model-inversion to quantify chlorophyll content (Fig 4d, according to (Verrelst et al., 2012, Verrelst et al., 2013)), and sun-induced fluorescence at $760 \mathrm{~nm}\left(\mathrm{~F}_{760}\right.$; Fig. 4e and 5d). Dominant green crops in this area at the time of observation was sugar beet with some corn and grassland fields (Fig. 4f), but the two vegetation types were in contrasting periods of their seasonal cycle. Sugar beet was still growing in the 2013 survey and had a dense fully mature canopy late summer 2012. In grassland the development was opposite, they had a dense vegetation cover in the early summer survey but already reached senescence in late summer. A visual evaluation already indicates that fluorescence shows a different pattern compared to other vegetation variables. Additionally, all surfaces having no active chlorophyll are characterized with zero fluorescence emissions, demonstrating a high contrast between active vegetation and all other surfaces. To better understand the correlations of $\mathrm{F}_{760}$ with other vegetation properties, we investigated approximately 75 fields (excluding field borders).

Average $\mathrm{F}_{760}$ from fields is related to other vegetation properties but adds new information. $\mathrm{F}_{760}$ increases with NDVI, indicative for biomass in the respective field, while NDVI values saturate at values around 0.8. NDVI is known to saturate at dense vegetation because the signal is mainly dominated by reflectance from the outermost canopy. The comparison with EVI, which is known to be less affected by saturation in dense canopies showed a slightly more linear correlation at dense canopies. However, the relation between $\mathrm{F}_{760}$ and NDVI values showed a clear deviation of a simple correlation and different vegetation types clearly clustered. Additionally, the seasonality of sugar beet and grassland was clearly visible in this analysis (Fig. 6a). Sugar beet was growing between early and late summer, while grasslands were mown and approached senescence towards late summer. This is reflected in the temporal shift in the two clusters and it is noteworthy that the two seasonal changes have opposite directions, but also happen with a different slope. Senescence of grassland in late 
summer is associated with a larger decline in $\mathrm{F}_{760}$, while $\mathrm{F}_{760}$ values of the perennial sugar beet remain high throughout the summer (Fig. 6a).

The correlation of $\mathrm{F}_{760}$ with the remotely quantified chlorophyll content showed also high variability between both parameters. However, different crop types showed clear clusters in the correlation analysis. Sugar beet fields had highest fluorescence values, distinguishing this cluster from that of corn, which was already in the corn filling phase approaching senescence (Fig 6b).

In this paper, we only report sun-induced fluorescence at $760 \mathrm{~nm}\left(\mathrm{~F}_{760}\right)$ that corresponds to fluorescence emission in the far-red region. Because of the wider $\mathrm{O}_{2}-\mathrm{A}$ absorption band this fluorescence flux is easiest to quantify, but HyPlant data have high enough spectral and dynamic resolution that also fluorescence can be retrieved in the oxygen-B band (at $687 \mathrm{~nm}$ ) or taking the solar absorption lines around $755 \mathrm{~nm}$ into account $\left(\mathrm{F}_{687}\right)$. In the future, we can expect more advanced retrieval algorithms based on Spectral Fitting Methods that will reconstruct the whole fluorescence signal (Sabater et al., 2014). Studies that also retrieve fluorescence at the $\mathrm{O}_{2}-\mathrm{B}$ band $\left(\mathrm{F}_{687}\right)$ and thus quantify red fluorescence are under way, and validated data on both peaks will soon become available (first results are found in Rossini et al. 2015). Additionally, approaches that exploit fluorescence infilling in the solar absorption lines (Fraunhofer lines) will be further evaluated. These solar lines have the advantage that they are not influenced by the properties of the Earth atmosphere (Joiner et al. 2013) and thus may provide a valuable addition to the oxygen absorption lines. Despite their narrow nature, these Fraunhofer lines are clearly visible around $750 \mathrm{~nm}$ in the HyPlant data (Fig 1) and thus may provide a good test case to evaluate retrieval algorithms that are based on the different absorption features.

This study clearly indicates that $\mathrm{F}_{760}$ measures structural and functional properties of photosynthetic light conversion in canopies (Damm et al., 2010). It can be assumed that especially $\mathrm{F}_{760}$ also originates from deeper layers of the canopy because foliage has a high transmittance in this spectral region. Thus, $F_{760}$ can be used as an excellent indicator to selectively measure the amount of absorbed light in chlorophyll (see also hypothesis from (Rossini et al., 2010)). Additionally, we propose that sun-induced fluorescence is related to the activity of the photosynthetic machinery. This is supported by the high values of fluorescence in sugar beet. Leaf level measurements with the well-established PAM chlorophyll fluorescence system (Rascher et al., 2000) showed a physiological down-regulation in maize, while sugar beet still had maximum photosynthetic rates in

This article is protected by copyright. All rights reserved. 
September (Table 2). Thus, in the perennial sugar beet plants photosynthesis is still fully active, and no signs of senescence or chlorophyll breakdown happened during this time of the year. Additionally, the $\mathrm{C}_{4}$ species corn and Miscanthus sp. showed high values of fluorescence emission (E in Fig 3), which is in agreement to the findings of Guanter et al.(2014).

\section{Conclusions and future studies}

The sensitivity of $\mathrm{F}_{760}$ for the actual photosynthetic efficiency was often hypothesized and indicated in ground studies (e.g. (Damm et al., 2010)), but this is the first study demonstrating this property using airborne data and covering several species. $\mathrm{F}_{760}$ is not simply an improved measure of chlorophyll because different species and surpassingly different functional status cause a clear deviation from a simple 1:1 line between chlorophyll and $F_{760}$ (Fig 6). The relationship between $F_{760}$ and photosynthetic electron transport is mainly dependent of rate constants in the photosynthetic apparatus and thus is non-linear and may even show opposite relations depending if a plant is adapted to low or high light conditions (van der Tol et al. 2014). The potential of $\mathrm{F}_{760}$ to reflect the actual status of photosynthesis was recently demonstrated by applying a herbicide that selectively blocks photosynthetic electron transport leaving the total amount of pigments untouched. Ground and airborne measurements of $\mathrm{F}_{760}$ and $\mathrm{F}_{687}$ showed a dramatic 3-fold increase within a few hours indicating the functional block of actual photosynthetic rates (Rossini et al., 2015). Therefore, measurements of sun-induced fluorescence may fundamentally help to improve our local, regional, and global model, which are estimated to predict the spatio-temporal dynamics of photosynthetic carbon exchange rates. On the process scale, sun-induced fluorescence may help to better parameterize light absorption and conversion within the canopy (van der Tol et al., 2009), provide input to understand vegetation dynamics that occur on the scale of meters, and influence mesoscale (km scale) surface and atmosphere dynamics by non-linear scaling (Simmer et al. in press). On the largest scale, direct measurements of functional efficiency of photosynthesis may greatly reduce uncertainties in evergreen ecosystems, which are subjected to frost-induced activation and deactivation of photosynthesis as well as seasonal droughts and other environmental constraints (Bergh et al., 1998). The two photosystems contribute to these peaks, but their proportions are different. Most physiological stress regulating mechanisms are operational on photosystem II, thus functional regulation will 
affect the first peak of the fluorescence emission to a greater extend. Therefore measuring both peaks will improve our ability to understand and predict the dynamic nature vegetation stress response that is an interplay between functional and structural regulation (Agati, 1998, Daumard et al., 2010, Flexas et al., 2002, Fournier et al., 2012, Pfündel, 1998, Thoren et al., 2010).

Thus, sun-induced fluorescence may serve as an early indicator of photosynthetic limitation in local, regional, and global carbon modeling. Additionally, it may serve as a novel indicator for precision agriculture and large-scale management of agricultural production in a future bioeconomy. Photosynthesis often does not directly determine final agricultural yield, but limitations of the photosynthetic capacity are an excellent indicator for yield reductions (Long et al., 2006, Zhu et al., 2010), and sun-induced fluorescence, which can be mapped on the large scale, may provide a novel stress indicator (Guanter et al., 2014). In the future, the proposed FLEX satellite mission that is currently being evaluated by the European Space Agency and aims for a global fluorescence mapping may target these objectives on the large scale and could complement airborne measurements as presented in this paper.

\section{Acknowledgements}

We gratefully acknowledge the financial support by the SFB/TR 32 "Pattern in Soil-Vegetation-Atmosphere Systems: Monitoring, Modelling, and Data Assimilation” project D2, funded by the Deutsche Forschungsgemeinschaft (DFG). The European Space Agency (ESA) provided additional financial support within the framework of the HyFLEX campaign (ESA contract 4000107143/12/NL/FF/If). Data were acquired during the joint SFB/TR32 and ESA funded HyFlex campaign. HyPlant was developed by a large-scale investment grant of the Helmholtz Association.

\section{Author contributions}

U. Rascher conceived the study and designed HyPlant. He was PI of the campaigns and organized data acquisition and analysis with the assistance of J. Moreno, M. Drusch, and D. Schüttemeyer. T. Hyvärinen, J. Jussila, and K. Kataja developed and built HyPlant and performed the laboratory characterization and calibration of the instrument. S. Kraft supported the instrument development and calibration activities. A. Burkart, F. Pinto, and A. Schickling operated HyPlant during the campaigns. F. Pinto and A. Damm developed the 
processing pipeline for fluorescence retrieval. F. Pinto and L. Prey processed all flight lines and retrieved fluorescence maps. J. Verrelst calculated the chlorophyll product. S. Cogliati, T. Julitta, M. Rossini, and M. Pikl performed the ground reference measurements and significantly contributed to the data analysis. P. Kokkalis provided the atmospheric data. C. Cilia produced the land cover classification. T. Kraska and R. Pude coordinate the scientific experiments on Campus Klein-Altendorf and contributed to interpretation of the results in Fig 3. O. Muller helped to interpret the physiological results. U. Rascher wrote the paper with discussions and contributions from all co-authors.

\section{Fig. 1}

Airborne imaging spectrometer HyPlant. (a) Schematic drawing of the HyPlant sensor consisting of the broad band dual module (A) and the high resolution fluorescence module (B). Additionally, the GPS/IMU positioning unit that is attached to the rack is shown (C). (b) Installation of HyPlant within a Cessna aircraft during 2012 campaign. In the back, the data acquisition unit is visible (D). (c, d) Representative radiance measurements from a bright target (black), dark target (blue), vegetation (green), and bare soil (red) from the dual and the fluorescence module, respectively. The spectrally high-resolution fluorescence module resolves the two oxygen absorption lines $\mathrm{O}_{2}-\mathrm{A}$ and $\mathrm{O}_{2}-\mathrm{B}$ at $760 \mathrm{~nm}$ and $687 \mathrm{~nm}$, respectively. Additionally water vapor absorption bands between 705 and $735 \mathrm{~nm}$ are visible. Even very narrow Fraunhofer lines that are due to absorption features in the solar atmosphere are visible at $750 \mathrm{~nm}$.

\section{Fig. 2}

Validation of airborne HyPlant $\mathbf{F}_{760}$ measurements. (a) Comparison of ground- and airborne-based fluorescence values from two selected crop types and soil. Black dots correspond to sun-induced fluorescence $\left(\mathrm{F}_{760}\right)$ retrievals from data flown $600 \mathrm{~m}$ above ground, and grey dots represent $\mathrm{F}_{760}$ values retrieved form data flown 1,780 $\mathrm{m}$ above ground. Error bars indicate the spatial variability of $\mathrm{F}_{760}$ within the selected areas. (b) Fluorescence values measured from low (600 $\mathrm{m}$ above ground) and high (1,780 $\mathrm{m}$ above ground) overpasses. Corresponding fields were manually selected and the field average of fluorescence values at $760 \mathrm{~nm}$ was compared between the two flight heights.

This article is protected by copyright. All rights reserved. 


\section{Fig. 3}

\section{Fluorescence maps of the agricultural research station Campus Klein-Altendorf,}

University Bonn, Germany. (a): pseudo-RGB composite from the research station. (b):

Fluorescence map measured using the HyPlant sensor from $600 \mathrm{~m}$ above ground resulting in a pixel resolution of $1 \mathrm{~m}^{2}$. Sun-induced fluorescence at $760 \mathrm{~nm}\left(\mathrm{~F}_{760}\right)$ was calculated according to the modified 3FLD method in the oxygen $\mathrm{O}_{2}$-A line. Fluorescence is expressed in physical units and atmospheric correction was applied to calculate top-of-canopy fluorescence. Different vegetation types and plots of the research station show greatly different fluorescence emission: (A) bare and foil-covered soil and in the center roofs, streets and parking lots of the experimental station; (B and C) commercial and experimental apple tree plantations. Significantly, the highest fluorescence was recorded from the sugar beet fields (D) and from the experimental plots of the perennial $\mathrm{C}_{4}$ species Miscanthus sp. and different corn varieties (E). Image was recorded 23 August 2012, 15:33 local time (UTC + 2h) $\left(50^{\circ} 37^{\prime} \mathrm{N} 6^{\circ} 59^{\prime} \mathrm{E}\right)$..

\section{Fig. 4}

\section{Airborne maps of different vegetation products and sun-induced fluorescence $\left(F_{760}\right)$}

from an agricultural area in Western Germany derived from the fluorescence module of the HyPlant instrument.

The flight line was recorded on 23 August 2012 from $600 \mathrm{~m}$ height, at 13:50 local time (UTC $+2 \mathrm{~h}$ ), which was approximately 1 hour after solar noon. The area is area dominated by agricultural fields south of the city of Jülich, Germany $\left(50^{\circ} 52^{\prime} \mathrm{N} 6^{\circ} 27^{\prime} \mathrm{E}\right)$. The flight line was geo-referenced and at-sensor radiances were calculated using the laboratory calibration files. (a) For the pseudo-RGB image reflectance bands at $696 \mathrm{~nm}, 708 \mathrm{~nm}$, and $677 \mathrm{~nm}$ are used for the red, green, and blue channel of the image. (b) $\mathrm{I}_{758}$ refers to the top-of-canopy radiance at $758 \mathrm{~nm}$. (c) The normalized difference vegetation index NDVI was calculated as $N D V I=\frac{R_{758}-R_{670}}{R_{758}+R_{670}}$. (d) Leaf chlorophyll content (LCC) was calculated using the Gaussian process regression method (Verrelst et al., 2012, Verrelst et al., 2013). (e) Sun-induced fluorescence $\left(\mathrm{F}_{760}\right)$ was calculated using the 3FLD method with an empirical correction of effective transmittance in the relevant wavebands. (f) Land cover classification was obtained through a supervised classification approach.

This article is protected by copyright. All rights reserved. 


\section{Fig. 5}

\section{Airborne maps of different vegetation products and sun-induced fluorescence $\left(F_{760}\right)$}

\section{from the sanme study site as in Fig. 4 derived from the fluorescence module of the}

\section{HyPlant instrument.}

The flight line was recorded on 18 June 2013 from $600 \mathrm{~m}$ height, at 13:32 local time (UTC + 2h) $\left(50^{\circ} 52^{\prime} \mathrm{N}^{\circ} 27^{\prime} \mathrm{E}\right)$. Vegetation indices and sun-induced fluorescence were derived based on the same algorithms as in Fig. 4. The EVI was calculated according to eq.9 (Huete et al 1997)

\section{Fig. 6}

\section{Correlation analysis of sun-induced fluorescence $\left(F_{760}\right)$ with other remote sensing vegetation properties.}

From the flight line of Fig 4 and 5, we manually selected about 75 regions of interest (ROI) in homogeneous fields or regions within fields regions. High spatial variability and edges of the fields were avoided. During time of overpasses green vegetation was dominated by sugar beet, corn, and grasslands. ROIs differed in size ranging from 1,059 to 71,508 pixels with an average size of 13,597 pixels. From the ROIs, mean and standard deviations were calculated and plotted. The color of the symbols represents the crop type shown in Figure 4f.

\section{References}

Agati G (1998) Response of the in vivo chlorophyll fluorescence spectrum to environmental factors and laser excitation wavelength. Pure and Applied Optics, 7, 797-807.

Alonso L, Gomez-Chova L, Vila-Frances J, Amoros-Lopez J, Guanter L, Calpe J, Moreno J (2008) Improved Fraunhofer line discrimination method for vegetation fluorescence quantification. IEEE Geoscience and Remote Sensing Letters, 5, 620-624.

Asner GP, Martin RE, Carlson KM, Rascher U, Vitousek PM (2006) Vegetation-climate interactions among native and invasive species in Hawaiian rainforest. Ecosystems, 9 , 1106-1117.

Barton CVM, North PRJ (2001) Remote sensing of canopy light use efficiency using the photochemical reflectance index: Model and sensitivity analysis. Remote Sensing of Environment, 78, 264-273.

Bergh J, Mcmurtrie RE, Linder S (1998) Climatic factors controlling the productivity of Norway spruce: A model-based analysis. Forest Ecology and Management, 110, 127-139.

Berk A, Cooley TW, Anderson GP et al. (2004) MODTRAN5: A reformulated atmospheric band model with auxiliary species and practical multiple scattering options. Remote Sensing of Clouds and the Atmosphere Ix, 5571, 78-85.

This article is protected by copyright. All rights reserved. 
Carlson TN, Ripley DA (1997) On the relation between NDVI, fractional vegetation cover, and leaf area index. Remote Sensing of Environment, 62, 241-252.

Damm A, Elbers J, Erler A et al. (2010) Remote sensing of sun-induced fluorescence to improve modeling of diurnal courses of gross primary production (GPP). Global Change Biology, 16, 171-186.

Damm A, Erler A, Hillen W, Meroni M, Schaepman ME, Verhoef W, Rascher U (2011) Modeling the impact of spectral sensor configurations on the FLD retrieval accuracy of sun-induced chlorophyll fluorescence. Remote Sensing of Environment, 115, $1882-1892$.

Damm A, Guanter L, Laurent VCE, Schaepman ME, Schickling A, Rascher U (2014) FLD-based retrieval of sun-induced chlorophyll fluorescence from medium spectral resolution airborne spectroscopy data. Remote Sensing of Environment, 147, 256-266.

Daumard F, Champagne S, Fournier A, Goulas Y, Ounis A, Hanocq JF, Moya I (2010) A field platform for continuous measurement of canopy fluorescence. IEEE Transactions on Geoscience and Remote Sensing, 48, 3358-3368.

Dolman AJ, Gerbig C, Noilhan J, Sarrat C, Miglietta F (2009) Detecting regional variability in sources and sinks of carbon dioxide: a synthesis. Biogeosciences, 6, 1015-1026.

Flexas J, Escalona JM, Evain S, Gulias J, Moya I, Osmond CB, Medrano H (2002) Steady-state chlorophyll fluorescence (Fs) measurements as a tool to follow variations of net $\mathrm{CO}(2)$ assimilation and stomatal conductance during water-stress in $\mathrm{C}(3)$ plants. Physiologia Plantarum, 114, 231-240.

Fournier A, Daumard F, Champagne S, Ounis A, Goulas Y, Moya I (2012) Effect of canopy structure on sun-induced chlorophyll fluorescence. ISPRS Journal of Photogrammetry and Remote Sensing, 68, 112-120.

Frankenberg C, Fisher JB, Worden J et al. (2011) New global observations of the terrestrial carbon cycle from GOSAT: Patterns of plant fluorescence with gross primary productivity. Geophysical Research Letters, 38, L17706.

Garbulsky MF, Peñuelas J, Gamon J, Inoue Y, Filella I (2011) The photochemical reflectance index (PRI) and the remote sensing of leaf, canopy and ecosystem radiation use efficiencies: A review and meta-analysis. Remote Sensing of Environment, 115, 281-297.

Guanter L, Alonso L, Gomez-Chova L, Amoros-Lopez J, Vila J, Moreno J (2007) Estimation of solar-induced vegetation fluorescence from space measurements. Geophysical Research Letters, 34.

Guanter L, Frankenberg C, Dudhia A et al. (2012) Retrieval and global assessment of terrestrial chlorophyll fluorescence from GOSAT space measurements. Remote Sensing of Environment, 121, 236-251.

Guanter L, Zhang YG, Jung M et al. (2014) Global and time-resolved monitoring of crop photosynthesis with chlorophyll fluorescence. Proceedings of the National Academy of Sciences of the United States of America, 111, E1327-E1333.

Hall F.G., Hilker T., Coops N.C., Lyapustin A., Huemmrich K.F., Middleton E., Margolis H., Drolet G., Black T.A. (2008) Multi-angle remote sensing of forest light use efficiency by observing PRI variation with canopy shadow fraction. Remote Sensing of Environment 112, 3201-3211.

Hilker T., Lyapustin A., Hall F.G., Wang Y.J., Coops N.C., Drolet G., Black T.A. (2009) An assessment of photosynthetic light use efficiency from space: Modeling the atmospheric and directional impacts on PRI reflectance. Remote Sensing of Environment, 113, 2463-2475.

This article is protected by copyright. All rights reserved. 
Huete, A.R., H. Liu, K. Batchily, and W. van Leeuwen (1997) A Comparison of Vegetation Indices Over a Global Set of TM Images for EOS-MODIS. Remote Sensing of Environment 59, 440-451.

Joiner J, Guanter L., Lindstrot R., Voigt M., Vasilkov A.P., Middleton E.M., Huemmrich K.F., Yoshida Y., Frankenberg C. (2013) Global monitoring of terrestrial chlorophyll fluorescence from moderate spectral resolution near-infrared satellite measurements: Methodology, simulations, and application to GOME-2. Atmos Meas Tech Discuss 6, 3883-3930.

Joiner J, Yoshida Y, Vasilkov AP, Yoshida Y, Corp LA, Middleton EM (2011) First observations of global and seasonal terrestrial chlorophyll fluorescence from space. Biogeosciences, 8, 637-651.

Long SP, Zhu XG, Naidu SL, Ort DR (2006) Can improvement in photosynthesis increase crop yields? Plant Cell and Environment, 29, 315-330.

Maier SW, Günther KP, Stellmes M (2003) Sun-induced fluorescence: A new tool for precision farming. In: Digital Imaging and Spectral Techniques: Applications to Precision Agriculture and Crop Physiology. (eds Van Toai T, Major D, Mcdonald M, Schepers J, Tartly L) pp Page. Madison, WI, American Society of Agronomy, Inc.; Crop Science Society of American, Inc.; Soil Science Society of American, Inc.

Malenovsky Z, Mishra KB, Zemek F, Rascher U, Nedbal L (2009) Scientific and technical challenges in remote sensing of plant canopy reflectance and fluorescence. Journal of Experimental Botany, 60, 2987-3004.

Meroni M, Barducci A, Cogliati S et al. (2011) The hyperspectral irradiometer, a new instrument for long-term and unattended field spectroscopy measurements. Review of Scientific Instruments, 82.

Meroni M, Busetto L, Colombo R, Guanter L, Moreno J, Verhoef W (2010) Performance of spectral fitting methods for vegetation fluorescence quantification. Remote Sensing of Environment, 114, 363-374.

Meroni M, Rossini M, Guanter L, Alonso L, Rascher U, Colombo R, Moreno J (2009) Remote sensing of solar-induced chlorophyll fluorescence: Review of methods and applications. Remote Sensing of Environment, 113, 2037-2051.

Panigada C, Rossini M, Meroni M et al. (2014) Fluorescence, PRI, and canopy temperature for water stress detection in cereal crops. International Journal of Applied Earth Observation and Geoinformation, 30, 167-178.

Pfündel E (1998) Estimating the contribution of Photosystem I to total leaf chlorophyll fluorescence. Photosynthesis Research, 56, 185-195.

Plascyk JA, Gabriel FC (1975) Fraunhofer line discriminator MKII: An airborne instrument for precise and standardized ecological luminescence measurement. Ieee Transactions on Instrumentation and Measurement, 24, 306-313.

Rascher U, Agati G, Alonso L et al. (2009) CEFLES2: the remote sensing component to quantify photosynthetic efficiency from the leaf to the region by measuring sun-induced fluorescence in the oxygen absorption bands. Biogeosciences, $\mathbf{6}$, 1181-1198.

Rascher U, Blossfeld S, Fiorani F et al. (2011) Non-invasive approaches for phenotyping of enhanced performance traits in bean. Functional Plant Biology, 38, 968-983.

Rascher U, Liebig M, Luttge U (2000) Evaluation of instant light-response curves of chlorophyll fluorescence parameters obtained with a portable chlorophyll fluorometer on site in the field. Plant Cell and Environment, 23, 1397-1405.

Rascher U, Nedbal L (2006) Dynamics of photosynthesis in fluctuating light - Commentary. Current Opinion in Plant Biology, 9, 671-678.

This article is protected by copyright. All rights reserved. 
Rossini M, Meroni M, Migliavacca M et al. (2010) High-resolution field spectroscopy measurements for estimating gross ecosystem production in a rice field. Agricultural and Forest Meteorology, 150, 1283-1296.

Rossini M., Nedbal L., Guanter L., Ač A., Alonso L., Burkart A., Cogliati S., Colombo R., Damm A., Drusch M., Hanus J., Janoutova R., Julitta T., Kokkalis P., Moreno J., Novotny J., Panigada C., Pinto F., Schickling A., Schüttemeyer D., Zemek F., Rascher U. (2015) Red and far red Sun-induced chlorophyll fluorescence as a measure of plant photosynthesis. Geophysical Research Letters, $\mathbf{4 2}$, doi:10.1002/2014GL062943.

Sabater N, Alonso L, Vicent J, Cogliati S, Verrelst J, Moreno J (2014) A fluorescence retrieval method for the FLEX Sentinel-3 tandem mission. In: Workshop on Hyperspectral Imaging and Signal Processing: Evolution in Remote Sensing (WHISPERS). pp Page, Lausanne, Switzerland.

Schurr U, Walter A, Rascher U (2006) Functional dynamics of plant growth and photosynthesis - from steady-state to dynamics - from homogeneity to heterogeneity. Plant Cell and Environment, 29, 340-352.

Thoren D, Thoren P, Schmidhalter U (2010) Influence of ambient light and temperature on laser-induced chlorophyll fluorescence measurements. European Journal of Agronomy, 32, 169-176.

Van Der Tol C, Verhoef W, Timmermans J, Verhoef A, Su Z (2009) An integrated model of soil-canopy spectral radiances, photosynthesis, fluorescence, temperature, and energy balance. Biogeosciences, 6, 3109-3129.

van der Tol, C., J. A. Berry, P. K. E. Campbell, and U. Rascher (2014), Models of fluorescence and photosynthesis for interpreting measurements of solar-induced chlorophyll fluorescence, J. Geophys. Res. Biogeosci., 119, doi:10.1002/2014JG002713.

Verhoef W, Bach H (2003) Simulation of hyperspectral and directional radiance images using coupled biophysical and atmospheric radiative transfer models. Remote Sensing of Environment, 87, 23-41.

Verhoef W, Bach H (2007) Coupled soil-leaf-canopy and atmosphere radiative transfer modeling to simulate hyperspectral multi-angular surface reflectance and TOA radiance data. Remote Sensing of Environment, 109, 166-182.

Verrelst J, Alonso L, Camps-Valls G, Delegido J, Moreno J (2012) Retrieval of vegetation biophysical parameters using Gaussian process techniques. IEEE Transactions on Geoscience and Remote Sensing, 50, 1832-1843.

Verrelst J, Rivera JP, Moreno J, Camps-Valls G (2013) Gaussian processes uncertainty estimates in experimental Sentinel-2 LAI and leaf chlorophyll content retrieval. ISPRS Journal of Photogrammetry and Remote Sensing, 86, 157-167.

Zarco-Tejada PJ, Catalina A, Gonzalez MR, Martin P (2013) Relationships between net photosynthesis and steady-state chlorophyll fluorescence retrieved from airborne hyperspectral imagery. Remote Sensing of Environment, 136, 247-258.

Zhu XG, Long SP, Ort DR (2010) Improving photosynthetic efficiency for greater yield. Annual Review of Plant Biology, 61, 235-261.

Simmer C., Masbou M., Insa Thiele-Eich I., Amelung W., Bogena H., Crewell S., Diekkrüger B., Ewert F., Hendricks Franssen H., Huisman J.A., Kemna A., Klitzsch N., Kollet K., Langensiepen M., Löhnert U., Rahman A.S.M.M., Rascher U., Schneider K., Schween J., Shao Y., Shrestha P., Stiebler M., Sulis M., Vanderborght J., Vereecken H., van der Kruk J., Waldhoff G., Zerenner T. (2014) Monitoring and modeling the terrestrial system from pores to catchments: The Transregional

This article is protected by copyright. All rights reserved. 
Collaborative Research Centre on Patterns in the Soil-Vegetation-Atmosphere

System. B Am Meteorol Soc. doi: 10.1175/BAMS-D-13-00134.1

Table 1: Characteristics of the HyPlant imaging spectrometer that was specifically designed for vegetation monitoring and to retrieve sun-induced fluorescence. HyPlant consists of two modules: (i) the broad band dual-channel module to measure surface reflectance in the visible and near infrared spectral region (380 to $2500 \mathrm{~nm}$ ) and (ii) the fluorescence module having a high spectral resolution in the red spectral range $(670$ to $780 \mathrm{~nm})$ that is designed for fluorescence retrievals. Performance characteristics given in this table were performed on flight data using several flight lines and a forward modelling of atmospheric absorption characteristics. Signal-to-noise ratios (SNR) (data in brackets) are calculated from laboratory measurements.

\section{Table 1: Performance characteristics of HyPlant}

\begin{tabular}{|c|c|c|c|}
\hline Sensor & \multicolumn{2}{|c|}{ Dual-Channel Module } & Fluorescence Module \\
\hline \multicolumn{4}{|l|}{ Spectral performance } \\
\hline Wavelength range [nm] & 380 to 970 & 970 to 2500 & 670 to 780 \\
\hline Bands & 350 & 272 & 1024 \\
\hline $\begin{array}{l}\text { Wavelength sampling } \\
\text { interval [nm] }\end{array}$ & 1.7 & 5.5 & 0.11 \\
\hline $\begin{array}{l}\text { Wavelength resolution } \\
\text { (FWHM) [nm] }\end{array}$ & 4.0 & 13.3 & $\begin{array}{l}0.25 \text { at } \mathrm{O}_{2}-\mathrm{A} \\
0.23 \text { at } \mathrm{O}_{2}-\mathrm{B}\end{array}$ \\
\hline Band broadening [nm] & 0.2 & 0.2 & $\begin{array}{l}0.01 \text { at } \mathrm{O}_{2}-\mathrm{A} \\
0.03 \text { at } \mathrm{O}_{2}-\mathrm{B}\end{array}$ \\
\hline Spectral shift [nm] & 1.2 & 2.4 & $<0.04$ \\
\hline Smiling [nm] & 0.4 & 1.2 & $\begin{array}{c}<0.01 \text { at } \mathrm{O}_{2}-\mathrm{A} \\
0.01 \text { at } \mathrm{O}_{2}-\mathrm{B}\end{array}$ \\
\hline \multicolumn{4}{|l|}{ Radiometric performance } \\
\hline SNR with full-scale signal & $(510)$ & $(1100)$ & (240) \\
\hline $\begin{array}{l}\text { Stay light and pixel cross talk } \\
{[\%]}\end{array}$ & & & $<0.5$ \\
\hline \multicolumn{4}{|l|}{ Spatial performance } \\
\hline Spatial pixels & 384 & 384 & 384 \\
\hline Field of view [deg] & \multicolumn{2}{|c|}{32.3} & 32.3 \\
\hline $\begin{array}{l}\text { Instantaneous field of view } \\
\text { [deg] }\end{array}$ & \multicolumn{2}{|c|}{0.0832} & 0.0832 \\
\hline Swath [m] & \multicolumn{2}{|c|}{$\begin{array}{l}380 \text { at } 600 \mathrm{~m} \mathrm{agl}^{1} \\
1140 \text { at } 1780 \mathrm{~m} \mathrm{agl}\end{array}$} & $\begin{array}{c}380 \text { at } 600 \mathrm{~m} \text { agl } \\
1140 \text { at } 1780 \mathrm{~m} \text { agl }\end{array}$ \\
\hline $\begin{array}{l}\text { Spatial sampling interval } \\
\text { (across track) [m] }\end{array}$ & \multicolumn{2}{|c|}{$\begin{array}{l}0.98 \text { at } 600 \mathrm{~m} \text { agl } \\
2.94 \text { at } 1780 \mathrm{~m} \text { agl }\end{array}$} & $\begin{array}{l}0.98 \text { at } 600 \mathrm{~m} \text { agl } \\
2.94 \text { at } 1780 \mathrm{~m} \text { agl }\end{array}$ \\
\hline
\end{tabular}

This article is protected by copyright. All rights reserved. 


\begin{tabular}{|l|c|c|c|}
\hline Sensor type & & & \\
\hline Type & CMOS & MCT & sCMOS $^{2}$ \\
\hline Dynamic range $[\mathrm{bit}]$ & 12 & 14 & 16 \\
\hline
\end{tabular}

${ }^{1}$ agl: above ground level.

${ }^{2}$ sCMOS: "scientific CMOS" chip - new CCD chip technology that combines different enhancements to achieve high light sensitivity with linear sensitivity.

Table 2: Changes in leaf level rates of maximum photosynthetic electron transport $\left(\mathrm{ETR}_{\max }\right)$ in sugar beet and maize between summer (July) and autumn (September) 2010. Data were recorded in the study area Selhausen (sugar beet: N 50.87142 ${ }^{\circ}$; 6.44792 ; maize: N 50.87304 ${ }^{\circ}$; E $6.44736^{\circ}$ ) using the Mini-PAM chlorophyll fluorescence yield analyser and a measurement protocol to derive light response characteristics (Rascher et al. 2000). Data were recorded at a minimum of 150 randomly selected leaves in the canopy. All data points are then fit with a simple non-linear model, and maximum electron transport rates of the

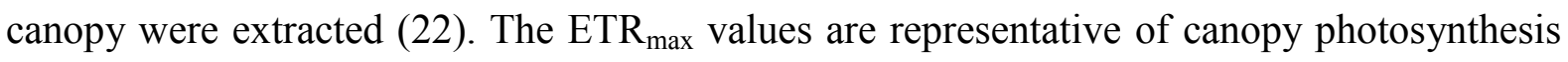
because they integrate of a large number of single leaves. Based on several years of measurements and the physiological stability of the crop varieties, it is safe to assume that similar trends occurred between the PAM measurements in 2010 and our airborne acquisition in 2012 .

\begin{tabular}{l|cc} 
& Summer (27 July) & Autumn (3 Sept) \\
\hline Maize & $253.1 \pm 7.2$ & $160.9 \pm 4.0$ \\
Sugar beet & $253.0 \pm 10.7$ & $296.8 \pm 19.7$
\end{tabular}

This article is protected by copyright. All rights reserved. 

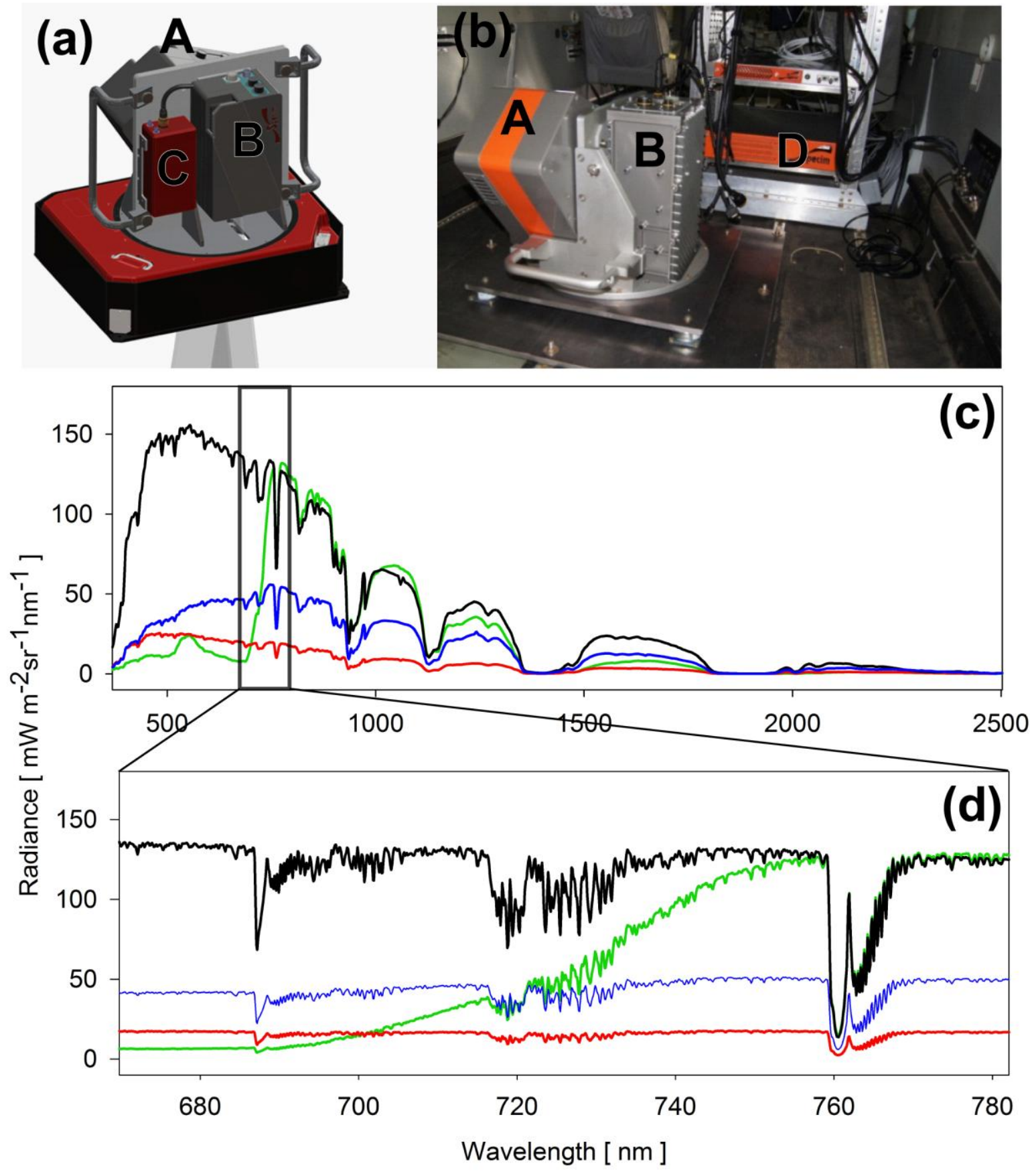

This article is protected by copyright. All rights reserved. 

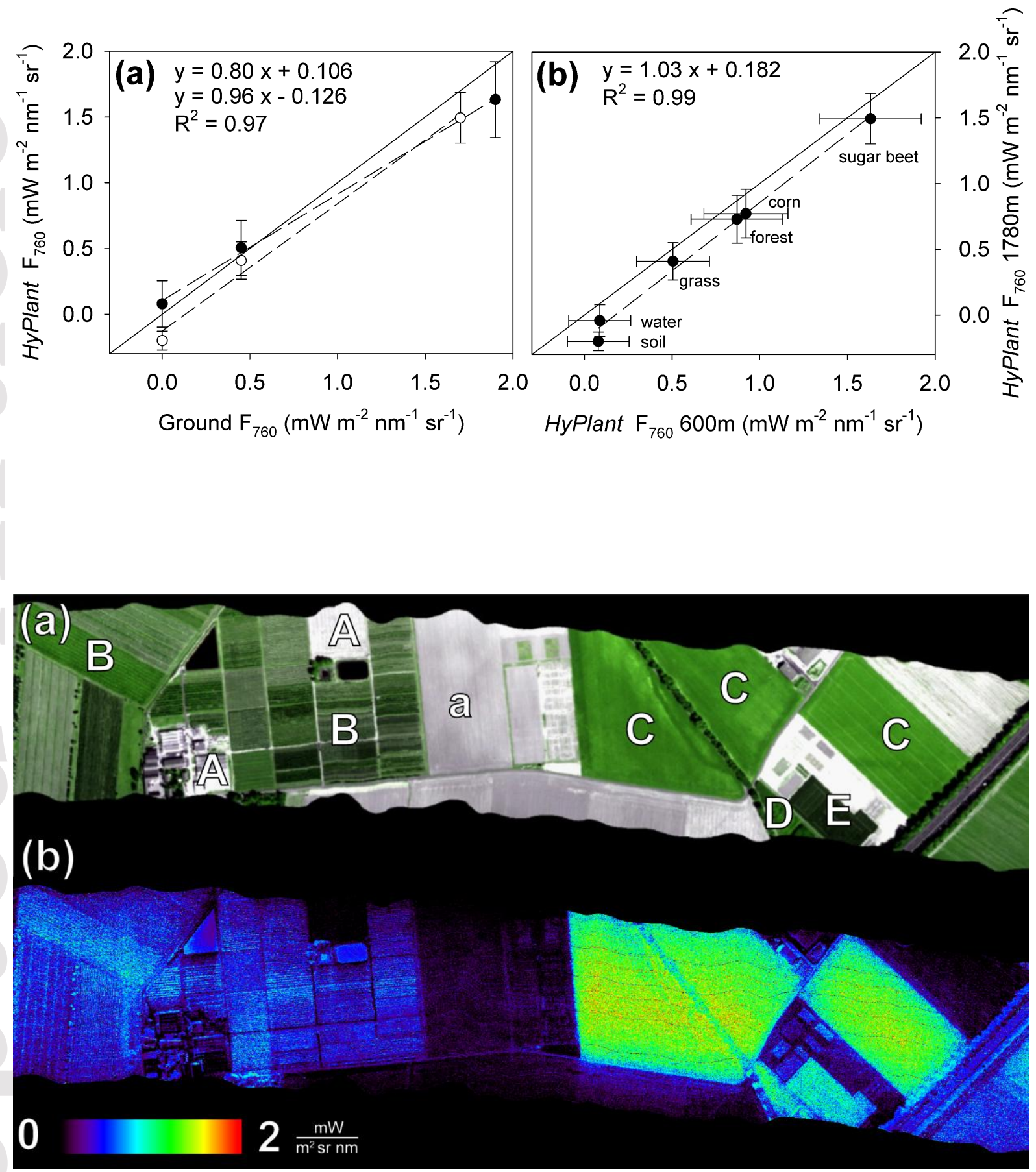

This article is protected by copyright. All rights reserved. 

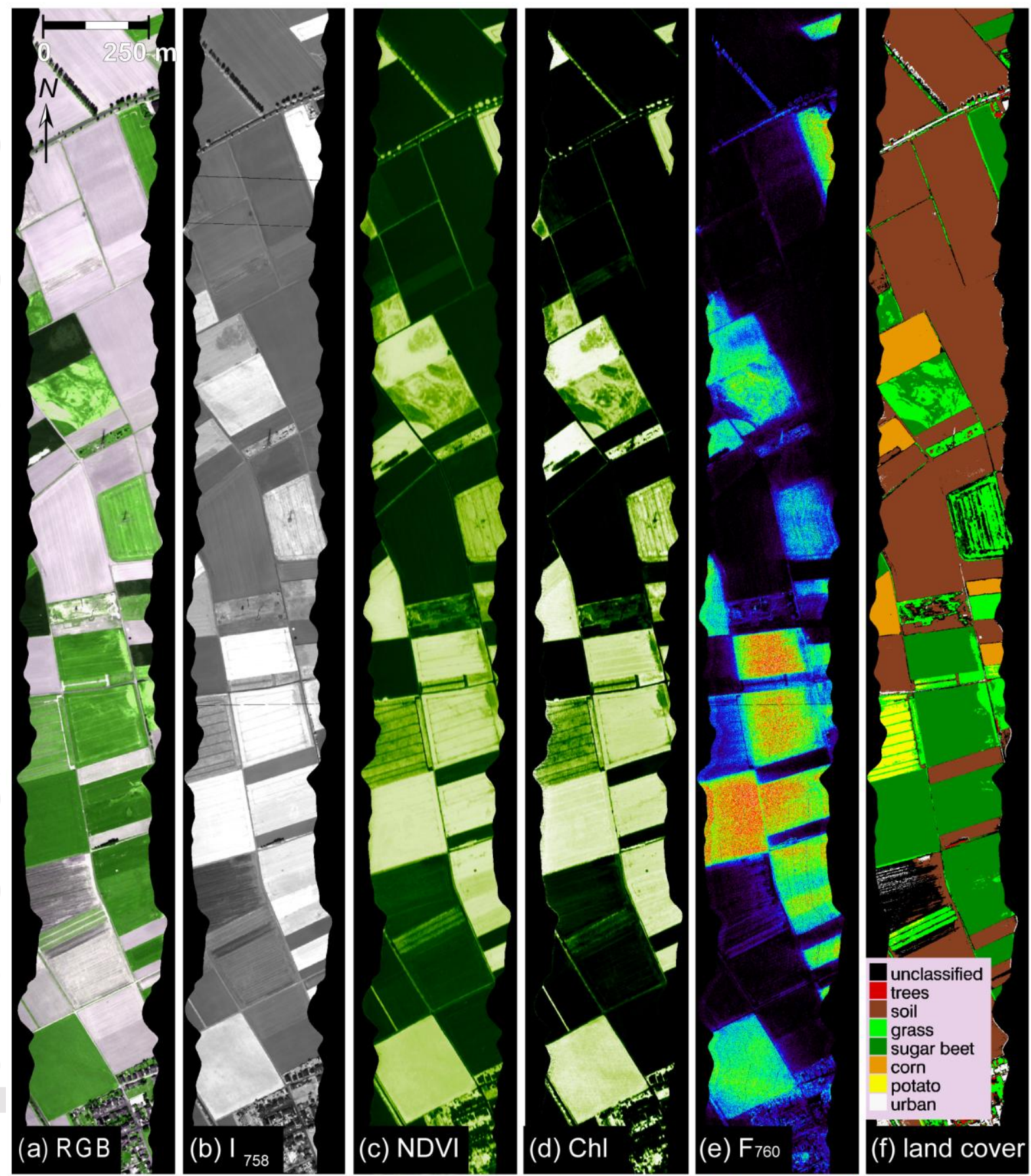

$\frac{0 \mathrm{~W} 0.150}{\mathrm{~m}^{2} \mathrm{srnm}}$

$10 \frac{\mathrm{mg}}{\mathrm{m}^{2}} 50 \frac{\mathrm{mW}}{\mathrm{m}^{2} \mathrm{srnm}} 3$

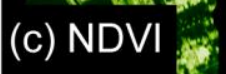

(e) $\mathrm{F}_{760}$

(f) land cover 


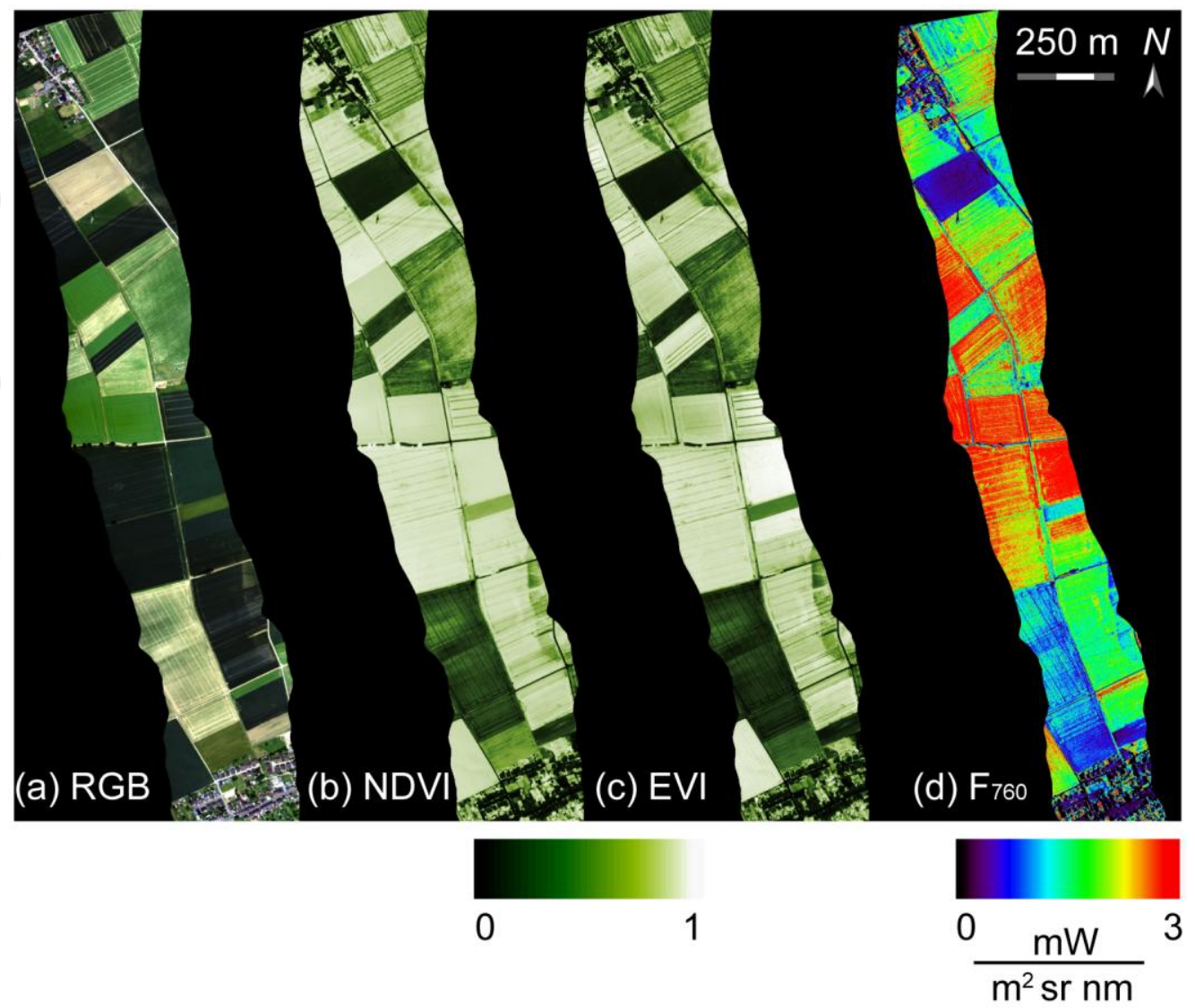

This article is protected by copyright. All rights reserved. 

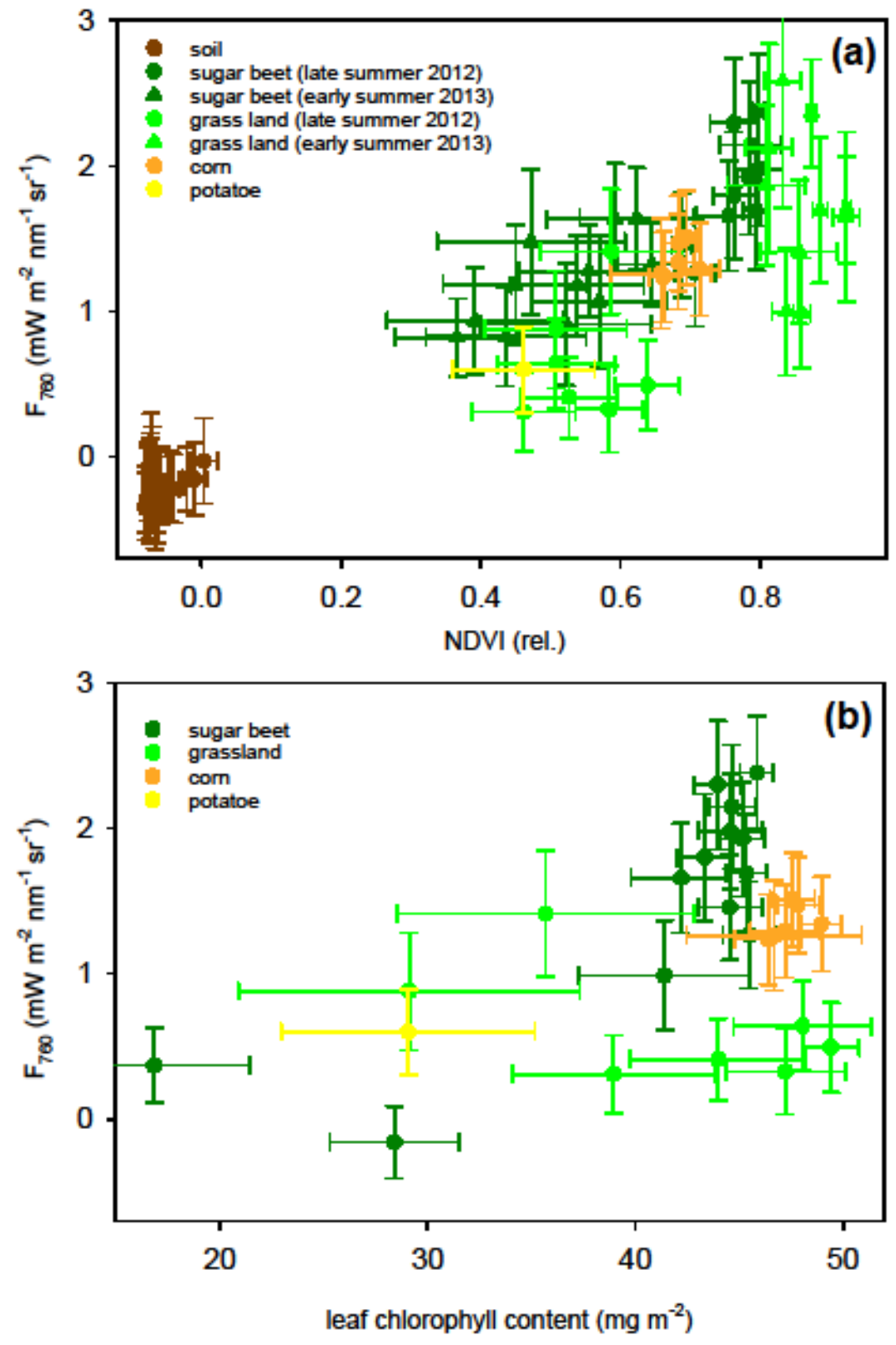

This article is protected by copyright. All rights reserved. 